\title{
Cybersecurity Program Designed for Future
}

\author{
Claudio R. Brito, PhD, Professor ${ }^{1}$, Melany M. Ciampi, PhD, Professor ${ }^{2}$, and Henrique D. Santos, PhD, Professor ${ }^{3}$ \\ ${ }^{1}$ COPEC President and IEEE Education Society President Emeritus, Brazil, drbrito@ copec.eu \\ ${ }^{2}$ WCSEIT President and IEEE Education Society Secretary, Brazil, drciampi@ copec.eu \\ ${ }^{3}$ University of Minho Professor and IEEE Education Society Vice President, Portugal, hsantos@ dsi.uminho.pt
}

\begin{abstract}
As a relatively new field with demand currently well above offer, good cybersecurity professionals can be difficult to find. This gives jobseekers some advantages such as: plentiful job openings; it is a candidates' market - for now; companies routinely pay top salary for cybersecurity and information security expertise; cybersecurity experts play critical roles in keeping companies and their customers safe. Taking these aspects into account it is possible to state that the right time to earn a degree in cybersecurity is right now. This paper has the goal to show a cyber security program specially designed for K12, the result of a research conducted to design a program for a private school that is investing viewing the possibility to enlarge its services in education field once it is a solid organization. Cybersecurity program at the level of K12 in fact a step to the expansion to Graduation programs for future.
\end{abstract}

Keywords -- information security; workforce; high skills; certification; career.

\section{INTRODUCTION}

As the foundation of a building, computer science and coding are the framework that supports many elements of the world in which humanity live. From security to banking for shopping, travel and social networking, people interact with computers and the code that controls them every day.

As cyber threats continue to grow in sophistication, organizations face a persistent challenge in recruiting skilled cyber security professionals capable of protecting their systems against the threat of malicious actors. With cybercriminals now responsible for billions in losses per year and state-sponsored hacking groups posing an ever-greater threat, the need for individuals capable of securing networks against attackers has never been greater. Workforce shortages exist for almost every position within cybersecurity, but the most acute needs are for highly-skilled technical staff. It is a promising profession in every level.

Cybersecurity professionals are tech experts who attempt to secure systems and thwart threats, so on demand and even more in a near future once Already gone the days of IT and security teams acted in silos. All IT professionals need to know the security and given the complexity of today's interconnected world; everyone has to work together to support the protection of the organization.

Cybersecurity encompasses a broad range of specialty areas and work roles, and no single education program can be expected to cover all of the specialized skills and sectorspecific knowledge desired by each employer. However, there are certain knowledge sets and skills that are essential for any new employee in a critical technical work role, regardless of the field they are in or the specialty they adopt. This includes an understanding of computer architecture, data, cryptography, networking, secure coding principles, and operating system internals, as well as working proficiency with Linux-based systems, fluency in low-level programming languages, and familiarity with common exploitation methods and mitigation techniques [1].

As with any new language, the earlier students are exposed to programming, the easier it will be to develop fluency and apply those skills in a wide range of careers in the future.

That is why in many countries computing has been taught at the level of $\mathrm{K} 8$ and $\mathrm{K} 12$, especially in high school where in some cases public and private schools offer cybersecurity courses with diploma that is valid to work in the area.

This paper has the goal to show a cyber security program specially designed for $\mathrm{K} 12$, the result of a research conducted to design a program for a private school.

\section{SOME ASPECTS OF COMPUTING}

What is the most widely spoken language in the world today?

The Binary Code - the language the computer understands.

A computer scientist can act in many areas: software engineering, database, bioinformatics, security, architecture, operating systems, game development, robotics, digital security, forensics, agronomy, agriculture, engineering and medicine.

Over half a million current jobs are in information technology fields such as software development, network administration and cyber security.

$65 \%$ of today's students will be in jobs that do not yet exist - Preparing them for this reality involves teaching computing that permeates all work activities, laser, transportation, infrastructure, etc [2].

Projections show a global deficit of 1.5 million cybersecurity professionals by 2020 in accordance with the Global Information Security Study [3].

Nowadays, everything is controlled by computers, so knowing that programming is becoming fundamental and therefore many countries are offering computer science in schools, including as part of curricula.

Teaching computer science since kindergarten has also been an encouraged activity in US schools, for example mostly programming or encoding and decoding.

Programming, for example, is able to help children develop various skills such as:

- the logical reasoning;

- the field of technology;

$17^{\text {th }}$ LACCEI International Multi-Conference for Engineering, Education, and Technology: "Industry, Innovation, And Infrastructure for Sustainable Cities and Communities", 24-26 July 2019, Jamaica. 
- problem solving because programming is solving problems;

- the creativity;

- the computational and systemic thinking;

- physics and mathematics.

In addition to helping develop other skills such as:

- cooperation;

- team work;

- and also, entrepreneurship;

- as well as helping to focus, focus, enhance selfconfidence and knowledge of English.

In some schools in the US for example they are teaching cybersecurity at the high school level with certification that prepares students to enter the job market [4].

\section{DEVELOPMENT OF THE PROGRAM}

The COPEC-Education Research Team has already a lot of experience designing and implementing different programs for different education organizations and this paper describes the one program that has been designed for a private school willing to foster the quality of its high school level viewing the future changes that education (in every level) will have.

The idea is to offer a new course that can enable the students either go to University or (as a new element) pursue a professional career or both.

After a large biographical research and visits to some institutions the team has designed a course that fits to the audience of that school. The choice has been based on the courses that are already been offered in the market and that makes sense for the purpose of having students with the knowledge that will enable them to go for work market or university or both. This in particular is based on the USA high school models.

The dosage of knowledge to teach is then on account of the teacher of each subject who can feel the class and so along the course can reach the goals with more fluency.

It has been taking into account the fact that the students have classes in one period, morning or afternoon what makes possible to have extra classes in another period. So, the students have the possibility to come in the morning or in the afternoon. The school already has already plenty of rooms for what has been named Cyber Labs.

New teachers were hired for this program and the acquisition of Lab material has been done based on the most pressing needs with a budget for further material acquisition in accordance with the future needs as well as the hiring of new teachers.

The expected results for a first year of implementation of the program will be measured at the end of 2019 once it is the first year of the program. A huge marketing strategy has been conducted and it seems promising the number of students enrolling the program. The emphasis has been on the future need of professionals in this area in any level, technical, under graduation and graduation once every enterprises, schools, government and people will need to protect their data.

The students are invited to enrol the program and pay an extra amount of money and they will have an extra year after $\mathrm{K} 12$ if their choice is to follow a professional career and go to the work market soon after finishing it. In fact, the internship period is critical and will show the quality of the program as well as will motivate students to study more and pursue this promising career in cybersecurity.

Until the 12 th year of k12 they will have a certification.

\section{THE CURRICULUM OF A CYBERSECURITY COURSE FOR K12 DEVELOPED BY THE COPEC-EDUCATION RESEARCH TEAM}

This Professional Career provides young students with the technical skills necessary to build a sustained career in the area of Information Security or Cybersecurity.

Along the way the materials, and their level, are evolving. The course is developed in order to provide with the themes identification of security threats and vulnerabilities, configuration of solutions that allow reduce the attack surface of various types of computer systems, as well as the implementation of different types of hardening methodologies. It addresses the importance of Incident some methods to prevent them.

It culminates in providing the experience and credibility to design, implement, and manage an information security program to protect organizations of growing sophisticated attacks.

The program has been developed following the suggestions of NICERC - National Integrated Cyber Education Research Center, in USA and adapted to the reality of the school geographic and students' profile [5]. The choice was made taking into account the solid work of this organization and that is of high quality.

\section{4-year high school curriculum}

- Up to 5 technology certifications upon successful completion each year, each with its own earning potential;

- Final Objective: certified ethical computer hacker;

- Hired to protect network defenses for organizations, finding shortcomings in technology security systems;

- Tremendous demand for this position today.

\section{Prerequisites}

- Students with medium level scores or above;

- Students who may not be interested in going to college, but who could enroll a technical career with responsibility and great earning potential;

- It is recommended that students have a reasonable knowledge of Algebra;

- Enthusiastic worker, hardworking, self-directed students.

\section{THE PROGRAM}




\section{- 1o. Year- IT Essentials 1 and 2}

- 1st. block - Overview of computer architecture, emphasizing the underlying design principles and their impact on computer performance. Everything related to desktop computers. Learning Outcomes: TIA Comp A + certification upon successful completion of certification test.

- 2nd. Year Cyber Defence 1 and 2

- 2nd. block - Computer Networks, "Comp TIA Network"

Introduction to computer communication from an engineering perspective.

It focuses on principles of computer communication and basic concepts of computer network architecture.

Labs used to reinforce concepts and develop networking skills.

- 3rd. block - Advanced computer networks, hardening principles

Introduces the student to computer network vulnerabilities, forms of attack, countermeasures and defence systems.

Tools to protect hardware and software are discussed.

Tools and facilities available for intruders and security are discussed.

Certifications upon successful completion of the course and test.

Comp TIA Network.

Comp TIA Security.

- 3rd. Year - Programming and Data Structure 1 and 2

- 4th. block -Programming and Data Structures

$\mathrm{C}++$ programming language.

Solving Algorithmic Problems.

Syntax and semantics, arithmetic expressions, operators, functional decomposition, file input and output, toggle and loop structures, matrix processing, and other related topics.

Laboratory work.

- 5th. block - Advanced JAVA Programming

Object-oriented programming course, concepts of studies, terminology and methodologies used in systems, languages and object-oriented applications.

Students will design and implement software systems and develop a complete understanding of design, systems and object-oriented (OO) applications.

$\mathrm{C}++$ Portfolio.

Wallet JAVA.

System Administration, I \& II

- 6th block - Computer Systems Technology

Focus on Microsoft Windows 2008.

Designed to provide critical knowledge and skills to deploy, manage, and troubleshoot servers in a networked environment.

The labs led the Microsoft IT Academy E-Learning Suite

- 7th. block - Computer Systems Technology
Focus on the Linux operating system.

Provides students with the knowledge and skills necessary to configure, administer, and troubleshoot servers in a networked environment.

Topics include security issues, user and group administration, directory and restore strategies and techniques, integrated mass storage technologies, and alternative client technologies.

Projected results for year 3:

Exam MCITP 70-646 or MTA Fundamentals of Windows and MTA Server Fundamentals, Comp TIA Linux +.

- 4th. Year - Ethics and Programming Language Research

- 8th. block - IT Basics - Skills for IT Professionals Ethics

Students learn the professional skills necessary to be successful in their careers.

Focus on ethical responsibilities.

Writing skills and oral presentations on computer science and life skills topics.

Ethical Computer Issues.

Ethics and Programming Language Research.

- 9th. block - IT Programming, System Penetration Testing

Immersions of students in a practical environment.

Exposure to a different method of achieving the best information security posture in an organization.

Students learn to perform penetration tests.

Students learn how perimeter defences work.

Students learn how intruders increase privileges and what steps can be taken to prevent and stop them.

Goals: Python, Ruby and Perl Portfolios.

Certification CEH.

\section{MethodOLOGY}

The following procedures were set for the accomplishment of the starting point of the proposed program:

- it consists of training modules, integrated in an optics of mixed sessions of theory and practice (when necessary);

- some modules are constituted by a period of inperson training;

- permanent monitoring at all the steps;

- content customized by the teacher;

- exercises and simulations of practical situations are elaborated, guaranteeing a more effective comprehension;

- the contents given during the course were developed by COPEC Education Research Team, in consultation with partner organizations, and are duly accompanied by didactic material, developed by the teachers to the students of the program.

VII. COPEC - SCIENCE AND EDUCATION RESEARCH ORGANIZATION 
COPEC - Science and Education Research Organization is a multidisciplinary institution, a leader in working for the advancement of education and science and its applications for the development of technologies in the service of society.

The activities, content, and services provided by COPEC, through courses, publications and consultancy, with national and international experts contribute to the promotion of the professional who wants to stay well informed of new scientific technological achievements.

COPEC enjoys respect and international recognition characterized by open discussion, free exchange of ideas, serious debate and a commitment to rigorous research.

Its most recent achievement the IIE - Institute of International Education is a bold and resilient source of innovation in higher education. It provides quality courses in different fields of science.

COPEC - Science and Education Research Organization was established as an organization in 1999 by a group of science and technology professionals and academics that wanted to create an organization with the goal of promoting research in the various fields of education, science and technology.

With an international network of knowledge and acting in several areas of knowledge COPEC offers special courses for students and professionals interested in to acquire the knowledge and skills, which they will need in their personal and professional lives.

The COPEC Education Research Team works with consulting and management services for all training needs and courses for educational institutions and companies.

COPEC Education Research Team has the expertise in creating customized programs to meet any need for an organization.

Our team is multidisciplinary and international with years of experience in the development and implementation of training courses and high education programs to promote quality education [6].

\section{FINAL REMARKS}

The most important aspect to be considered is that a good course at any level does not give the fish but teach them to fish. In other words, teaching to find solutions, to study, how to research and exchange experiences. This is much more important and useful than teaching a language or a tool.

Educators and educational institutions should ensure that cybersecurity curricula include a strong focus on the fundamentals of computing to help prepare students to take on critical technical roles. Teachers should work to incorporate practical learning opportunities, such as competitions, challenges and cybernetic lanes into cybersecurity curricula, to develop practical skills in students, and if possible, to partner with local employers to enable students to participate in learning and internships expose them to cyber-security work.
The latest and most disruptive technologies, along with the new cybernetic tools and threats that crop up every day, are challenging organizations not only in how they protect their infrastructure, but also how they require new platforms and intelligence for it. There is no perfect solution for cybercrime, but it is necessary to work unceasingly in order to have a secure future in cyber space.

Learning computing early enables future generations of humans to work and advance science, technology, and society.

\section{REFERENCES}

[1] Singer, Peter W., and Allan Friedman. Cybersecurity: What everyone needs to know. OUP USA, 2014.

[2] Stewart, Craig A., et al. "What is cyberinfrastructure." Proceedings of the 38th annual ACM SIGUCCS fall conference: navigation and discovery. ACM, 2010.

[3] https://www.ey.com/Publication/vwLUAssets/ey-global-informationsecurity-survey-2018-19/\$FILE/ey-global-information-security-survey2018-19.pdf

[4] Rowe, Dale C., Barry M. Lunt, and Joseph J. Ekstrom. "The role of cybersecurity in information technology education." Proceedings of the 2011 conference on Information technology education. ACM, 2011.

[5] https://nicerc.org/curricula/

[6] Brito, Claudio R.; Ciampi, Melany M.; Vasconcelos, Rosa. M.; Amaral, Luis A.; Santos, Henrique D.; Barros, Victor A. "Engineering Course Specially Designed to Face Retention Issue" Proceedings of the 45th SEFI Annual Conference SEFI, 2017. 